\title{
Performance Evaluation of Reinforced Concrete Roadbed for Slab Track on Clay Subgrade
}

\section{Yoshitsugu MOMOYA, Dr. Eng.} Assistant Senior Researcher,

\author{
Etsuo SEKINE, Dr. Eng.
}

Senior Researcher, Laboratory Head,

\section{Takatada TAKAHASHI}

Assistant Senior Researcher,

Track Structures \& Geotechnology Laboratory, Track Technology Division

\section{Osamu MARUYAMA}

Japan Railway Construction, Transport and Technology Agency

\begin{abstract}
A high bearing capacity for subgrade is essential to avoid excessive settlement in constructing slab tracks on earth structures. However, a soft diluvial clay layer was detected on part of a Tohoku-Shinkansen line under planning adjacent to the local town of Shichinohe. To address the problem, a double-line-integrated reinforced concrete roadbed was developed. We carried out detailed ground investigations to evaluate the performance of the concrete roadbed on the soft diluvial clay on which the slab track is to be constructed. We further carried out on-site cyclic loading tests involving the application of a vibration machine. Based on the results of these investigations and tests, we carried out FEM analysis to evaluate the deformation characteristics of the concrete roadbed. The results of the FEM analysis clarified that the double-line-integrated reinforced concrete roadbed was able to appropriately support slab track on the soft diluvial clay subgrade.
\end{abstract}

Keywords: slab track, concrete roadbed, clay subgrade, track, ground investigation, loading test

\section{Introduction}

Slab tracks were formerly constructed only on viaducts or in tunnels rather than on earth structures such as embankments or cuttings. This was because track maintenance becomes rather difficult once excessive settlement is induced due to the deformation of earth structures. However, by introducing strict quality control for the subgrade and applying a reinforced concrete roadbed, it has become possible to construct slab tracks even on earth structures[1]. As a result, slab tracks with concrete roadbeds have been widely applied on earth structures in current Shinkansen line construction.

To avoid excessive settlement of slab tracks due to subgrade deformation, subgrade with a high bearing capacity is required. In cases where the $\mathrm{N}$-value according to SPT (standard penetration testing) is lower than 4, ground improvement using a method such as deep mixing is necessary. However, a soft diluvial clay layer with a low $\mathrm{N}$-value was detected on the part of a TohokuShinkansen line under planning adjacent to the local town of Shichinohe. In this case, ground improvement is necessary in order to conform to earth structure design standards. An alternative would be to use ballasted track instead of slab track. However, those methods were not appropriate because ground improvement increases the initial cost and ballasted track increases the maintenance cost. The results of a preliminary survey indicated that the diluvial clay layer was in a sufficiently overconsolidated condition, and it was presumed that no residual settlement would be induced by train loads. If slab track can be introduced only with surface improvement of the subgrade, it will become possible to reduce the overall life cycle cost significantly.

Figure 1 shows the standard constitution of slab track for installation on earth structures. On such structures, slab tracks are installed on a concrete roadbed (the standard RC version). Figure 2, on the other hand,

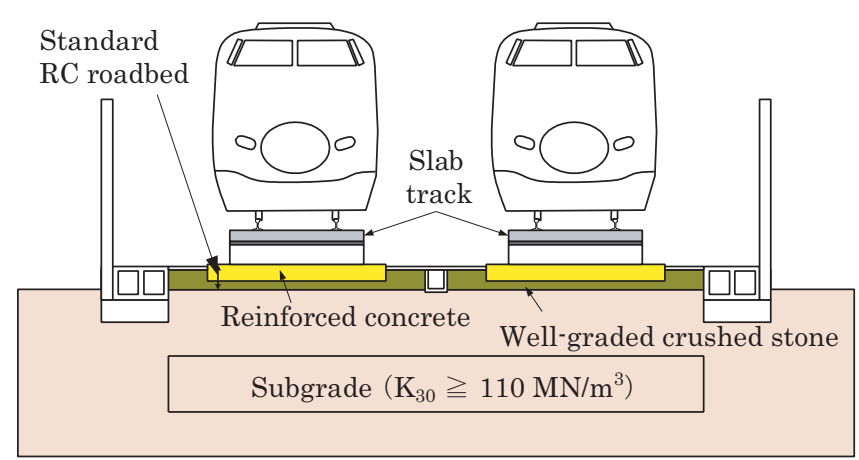

Fig. 1 Standard RC roadbed

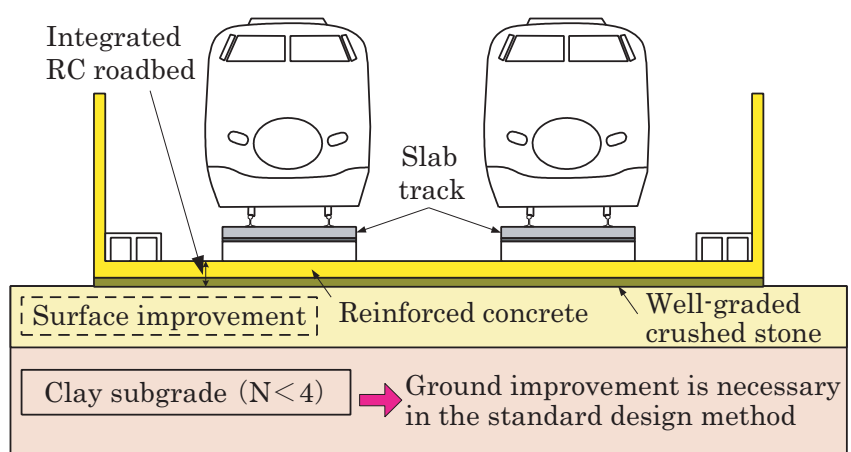

Fig. 2 Integrated RC roadbed 
shows the double-line-integrated reinforced concrete roadbed (the integrated $\mathrm{RC}$ version) we have developed for the construction of slab tracks on diluvial clay subgrade.

In this study, detailed ground investigation, in-situ cyclic loading tests and FEM were carried out to evaluate the performance of integrated $\mathrm{RC}$ roadbed.

\section{Overall constitution of performance evaluation}

Ground investigation and cyclic loading tests were carried out at a cutting section adjacent to Shichinohe Town between Hachinohe and Shin-Aomori. The testing site was situated $40 \mathrm{~m}$ above sea level on diluvial highland. Preliminary investigation detected soft diluvial clay in the subgrade, which consisted of volcanic cohesive soil and sediment clay. For surface improvement, the surface layer of the subgrade was substituted to the depth of one meter with well-graded crushed stone. This technique also prevents frost heaving.

Figure 3 gives the overview of performance evaluation for the integrated RC roadbed. For ground investigation, a standard penetration test (SPT), an electric cone penetration test (CPTU), plate load tests (PLT), physical property tests and triaxial compression tests were carried out. Then, a series of cyclic loading tests were carried out with the application of a vibration machine to evaluate roadbed displacement, reinforcing steel stress in the concrete roadbed, and subgrade stress. Additionally, FEM analysis was carried out to evaluate the deformation characteristics of the integrated $\mathrm{RC}$ roadbed. In this analysis, the deformation characteristics of standard $\mathrm{RC}$ roadbed and integrated $\mathrm{RC}$ roadbed were compared for evaluation of the integrated RC roadbed's performance.

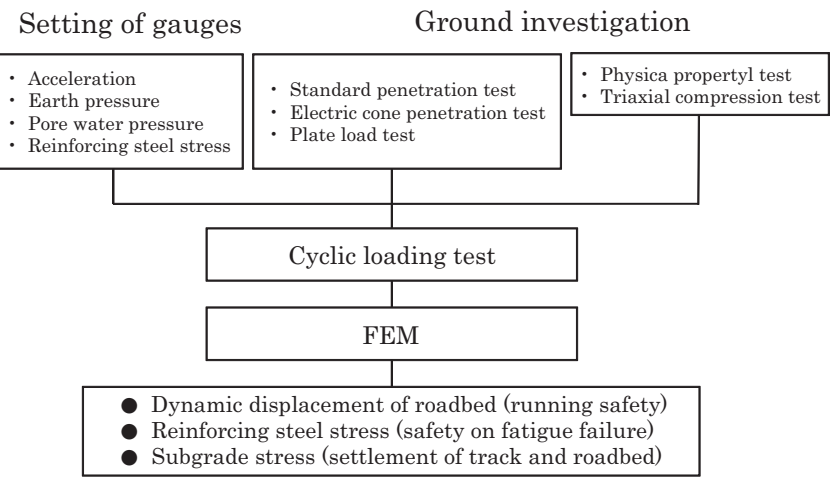

Fig. 3 Framework for performance evaluation

\section{Ground investigation}

\subsection{Test methods for ground investigation}

A standard penetration test (SPT), an electric cone penetration test (CPTU), plate load tests (PLT), physical property tests and triaxial compression tests were carried out to investigate the characteristics of the clay subgrade. SPT was carried out to the depth of $10 \mathrm{~m}$ from the ground surface. By using the boring hole for the SPT test, test samples for the triaxial compression test were obtained with a thin-walled tube sampler. To ascertain the physical properties of the subgrade clay, tests to establish the density of soil particles, water content, liquid limit, plastic limit and particle size distribution were performed.

Detailed ground information was obtained using CPTU. This test measured point resistance, side surface friction and pore water pressure consecutively to the depth of $10 \mathrm{~m}$. The plate loading test was carried out on both the clay subgrade and the subgrade with the improved surface.

\subsection{Ground investigation test results}

Table 1 shows the results of physical property testing. The sampled subgrade material showed a mixed aspect of volcanic cohesive soil and sediment clay. The results indicated that the water content and plasticity index vary in the direction of depth. On the other hand, the grain size distribution curve (Fig. 4) shows that the grain size distribution was almost the same among the tested samples.

Figure 5 shows the results of SPT and CPTU. Here, the surface of the subgrade was substituted to the depth of one meter with well-graded crushed stone. The SPT results indicated that the $\mathrm{N}$-value of the subgrade from the clay surface to a depth of $5 \mathrm{~m}$ was less than 4 . Under these conditions, slab track with standard RC roadbed cannot be applied without ground improvement. For the layer located deep down (below $5 \mathrm{~m}$ ), the $\mathrm{N}$-value increased up to around 10, which is still insufficient; however, this will not cause problems as the effects of train loads are negligible at this depth.

Table 1 Physical properties of the subgrade material

\begin{tabular}{|c|c|c|c|}
\hline & Depth $2 \mathrm{~m}$ & Depth $9 \mathrm{~m}$ & Depth $10 \mathrm{~m}$ \\
\hline Particle density $\left(\mathrm{g} / \mathrm{cm}^{3}\right)$ & 2.732 & 2.551 & 2.550 \\
\hline Water content (\%) & 55.2 & 222.1 & 63.1 \\
\hline Liquid limit (\%) & 62.2 & 254.0 & 117.6 \\
\hline Plastic limit (\%) & 26.3 & 88.5 & 40.8 \\
\hline Plasticity index (\%) & 35.9 & 165.5 & 76.8 \\
\hline
\end{tabular}

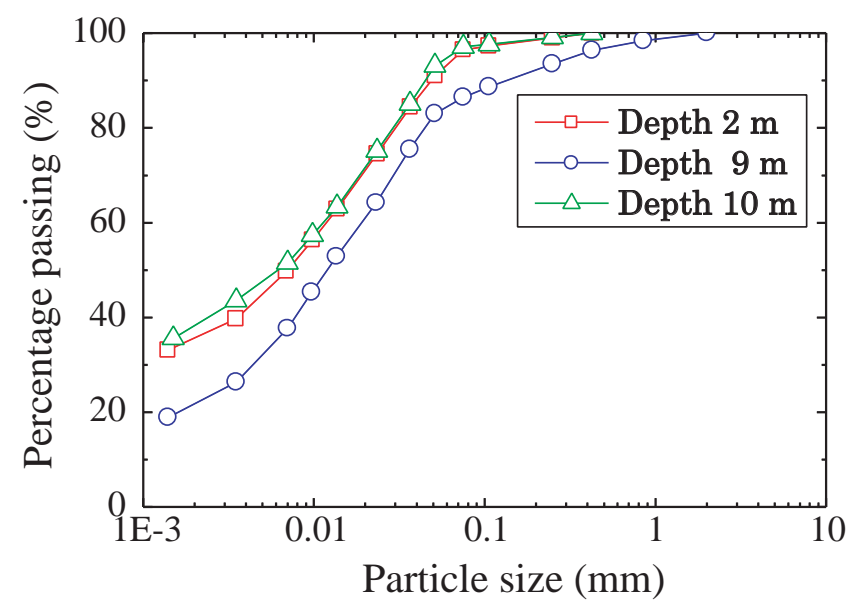

Fig. 4 Particle size distribution curve 


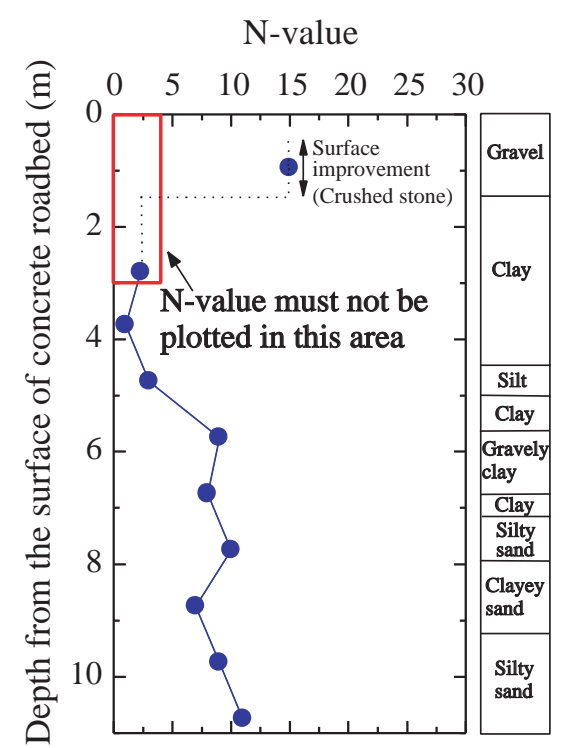

(a) Standard penetration test (SPT)
Point resitance $\mathrm{q}_{\mathrm{t}}\left(\mathrm{MN} / \mathrm{m}^{2}\right)$ Pore water pressure $\mathrm{u}_{\mathrm{d}}\left(\mathrm{kN} / \mathrm{m}^{2}\right)$ Side surface friction $\mathrm{f}_{\mathrm{s}}\left(\mathrm{kN} / \mathrm{m}^{2}\right)$
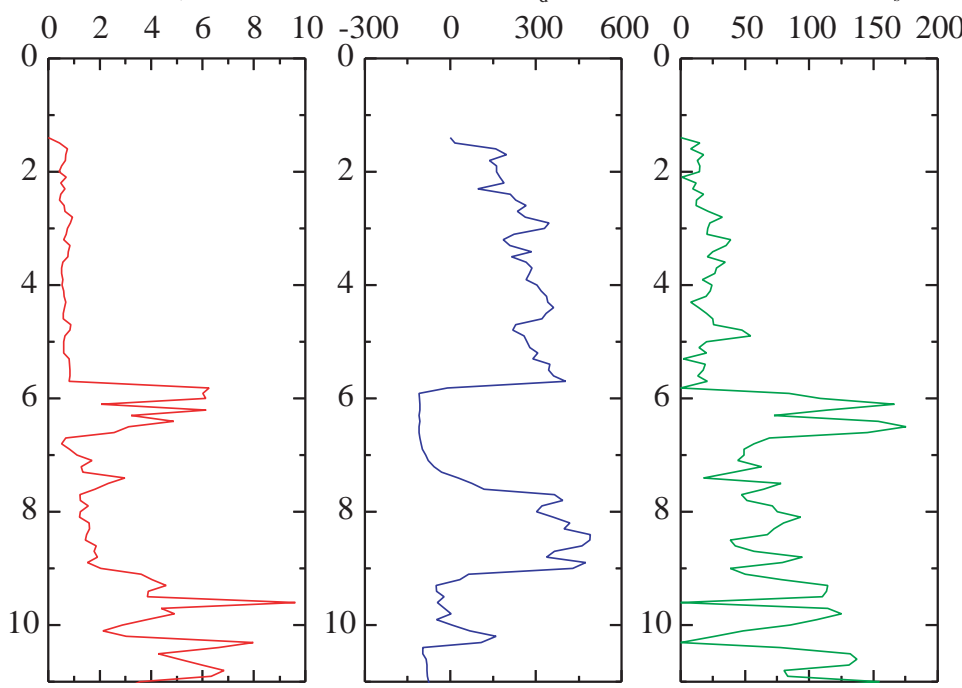

(b) Electric cone penetration test (CPTU)

Fig. 5 Standard penetration test and electric cone penetration test

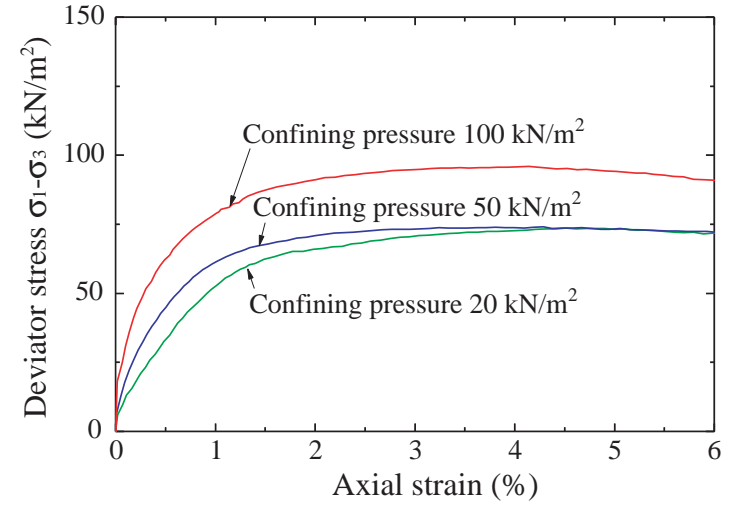

(a) Stress-strain relationship

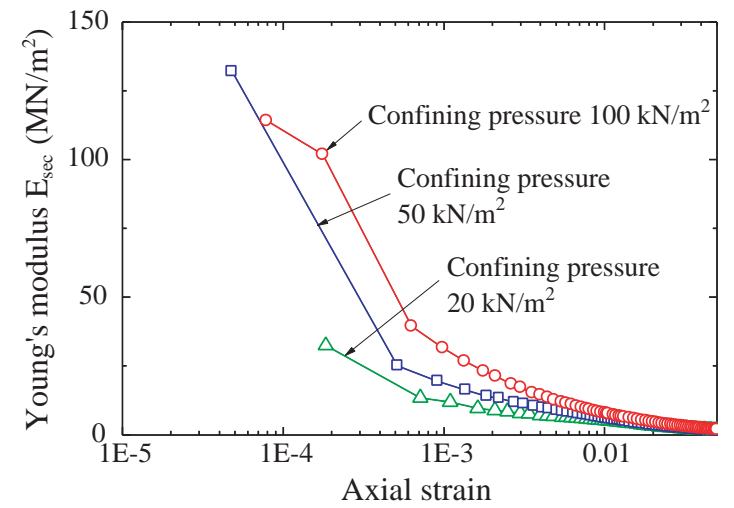

(b) Secant Young's modulus

Fig. 6 Results of consolidated unconfined triaxial compression testing

CPTU showed results similar to those of SPT. From the clay surface to a depth of $5-6 \mathrm{~m}$, point resistance and side surface friction were small, and pore water pressure was large. The point resistance and side surface friction increased at a depth of around $6 \mathrm{~m}$, while pore water pressure decreased, indicating particular sand-layer characteristics. In the layer located below a depth of $7 \mathrm{~m}$, point resistance and side surface friction decreased again before gradually increasing toward a depth of $10 \mathrm{~m}$.

Figure 6 shows the results of a consolidatedundrained triaxial compression test for which a specimen was sampled at the depth of $2 \mathrm{~m}$ from the subgrade surface. The maximum deviator stress was $75 \mathrm{kN} / \mathrm{m}^{2}$ in the case of a confining pressure of $20 \mathrm{kN} / \mathrm{m}^{2}$. In general, subgrade stress induced by train loads is around $20-30$ $\mathrm{kN} / \mathrm{m}^{2}$. Accordingly, the maximum deviator stress was large enough for the stress induced by train loads. Young's modulus was $30 \mathrm{MN} / \mathrm{m}^{2}$ in the case of a confining pressure of $20 \mathrm{kN} / \mathrm{m}^{2}$ and a strain level of $10^{-4}$. The Young's modulus value was large enough to support train loads properly, even though it was not as large as those of sand and gravel.

Table 2 shows the results of the plate load tests. The
Table 2 Plate load test results

\begin{tabular}{|c|c|}
\hline & $\mathrm{K}_{30}\left(\mathrm{MN} / \mathrm{m}^{3}\right)$ \\
\hline Clay subgrade & $\begin{array}{c}50,39,34 \\
(\text { Average 41) }\end{array}$ \\
\hline $\begin{array}{c}\text { Subgrade improvement } \\
\text { (well-graded crushed stone) }\end{array}$ & $\begin{array}{c}199,150,202 \\
\text { (Average 184) }\end{array}$ \\
\hline
\end{tabular}

average $\mathrm{K}_{30}$ value on clay subgrade was $41 \mathrm{MN} / \mathrm{m}^{3}$, which does not satisfy the reference value for supporting slab tracks stipulated in the design standard $\left(110 \mathrm{MN} / \mathrm{m}^{3}\right)$. On the other hand, the average $\mathrm{K}_{30}$ value on the subgrade improvement layer was $184 \mathrm{MN} / \mathrm{m}^{3}$, which indicated that the layer was properly constructed.

\section{Cyclic loading test}

\subsection{Cyclic loading test method}

Figure 7 shows the arrangement of the gauges and the vibration machine used in the cyclic loading test. In the subgrade, acceleration gauges, earth pressure gauges 


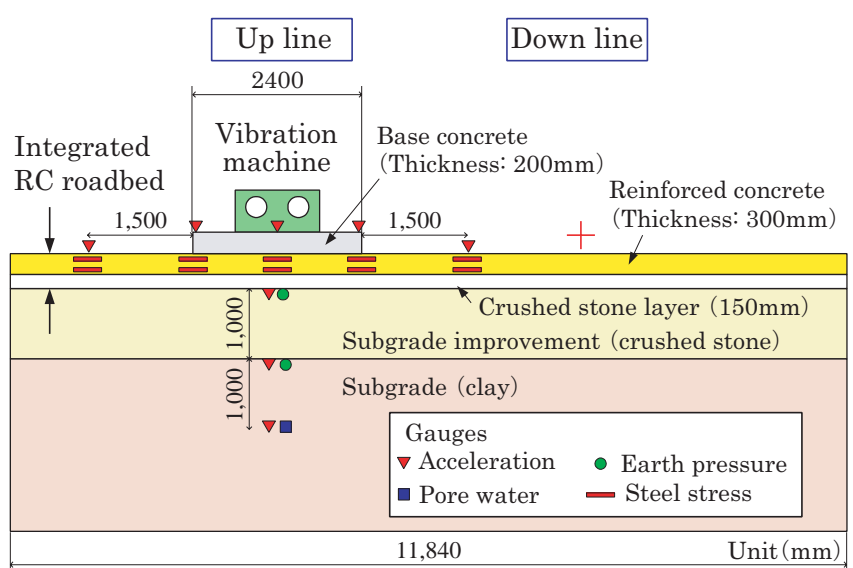

Fig. 7 Positioning of gauges and the vibration machine

and a pore water gauge were installed. In the concrete roadbed, reinforcing steel stress gauges were fitted. On the surface of the concrete roadbed, acceleration gauges were set to measure acceleration and estimate the dynamic displacement amplitude by integration of measured acceleration.

The vibration machine was installed $2,000 \mathrm{~mm}$ distant from the joint of the reinforced concrete. It was placed on a concrete base with the size of $200 \mathrm{~mm}$ (thickness) $\mathrm{x}$ $2,400 \mathrm{~mm}$ (width) built on the concrete roadbed, the size of which corresponded to that of the track slab.

In the cyclic loading test, a resonance test with changing frequencies was first carried out. Then, a cyclic loading test with 2 million loadings was performed.

\subsection{Cyclic loading test results}

In the resonance tests, cyclic loads of $\pm 10 \mathrm{kN}$ and \pm $20 \mathrm{kN}$ were applied. Figure 8 shows the relationship between the loading frequency and the total amplitude of displacement in these tests. The resonance frequency was approximately $6-7 \mathrm{~Hz}$, at which displacement was approximately 3.5 times larger than that at around $20 \mathrm{~Hz}$.

Figure 9 shows the acceleration, displacement, reinforcing steel stress and subgrade stress in the case of \pm $60 \mathrm{kN}$ with $20 \mathrm{~Hz}$ cyclic loading. The acceleration of the roadbed was the highest just beneath the vibration machine, while it became half of that $2,700 \mathrm{~mm}$ away from the loading point. Similarly, displacement was also the highest just beneath the vibration machine, while it be-

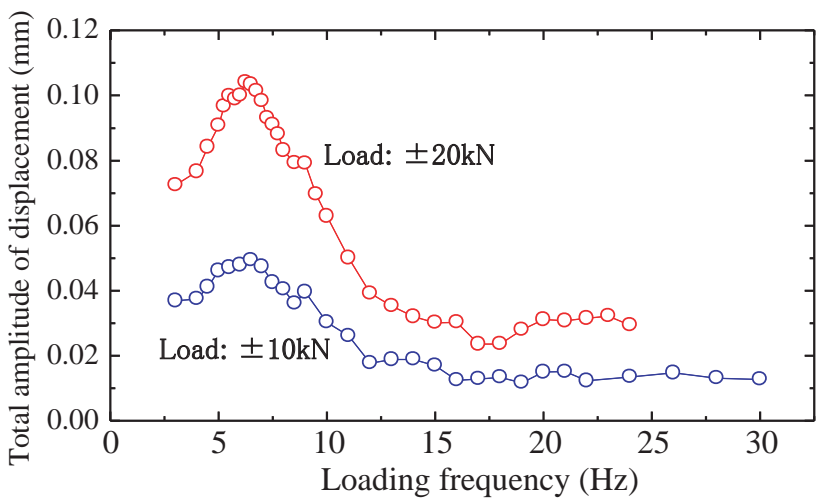

Fig. 8 Resonance test results

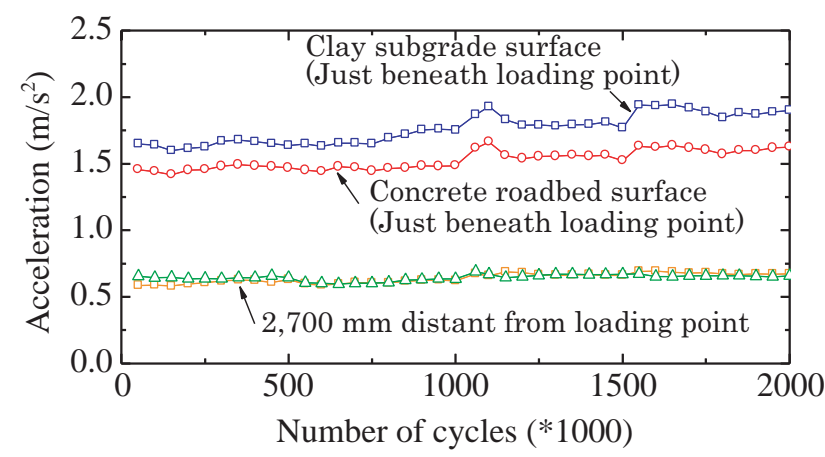

(a) Vertical acceleration

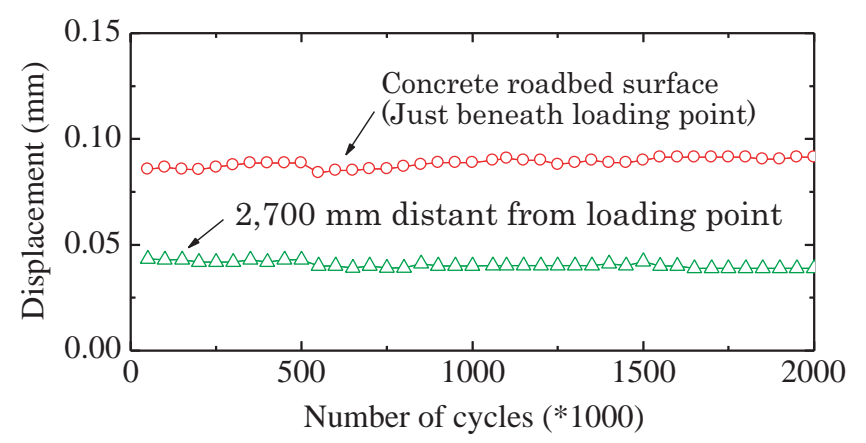

(b) Vertical displacement

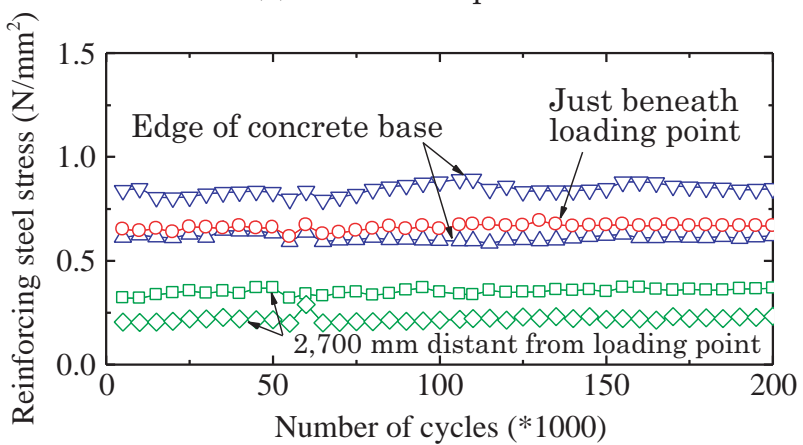

(c) Horizontal reinforcing steel stress

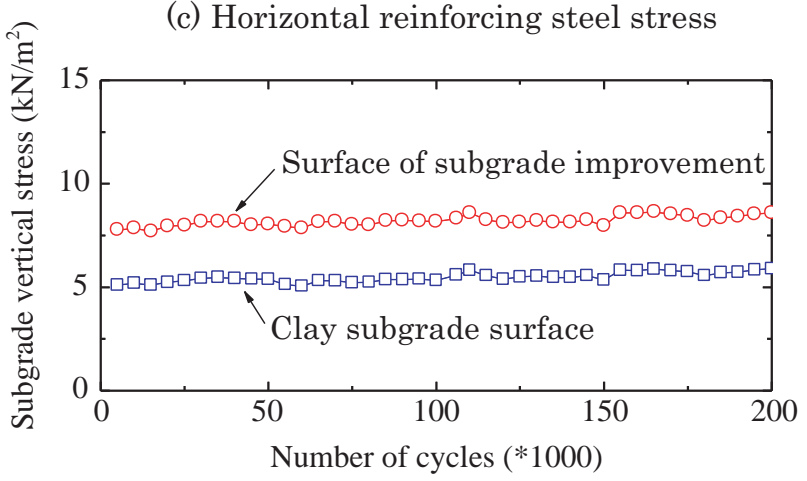

(d) Vertical subgrade stress

Fig. 9 Cyclic loading test results

came half of that $2,700 \mathrm{~mm}$ away from the loading point. The reinforcing steel stress was the highest at the edge of the concrete base with a width of $2,400 \mathrm{~mm}$, while it became half of that $2,700 \mathrm{~mm}$ away from the loading point. The vertical stress of the subgrade was approximately $8-9 \mathrm{kN} / \mathrm{m}^{2}$ on the subgrade improvement surface, while it was $5-6 \mathrm{kN} / \mathrm{m}^{2}$ on the original clay subgrade surface. These values are reasonably small, and 
remained constant during the cyclic loading tests.

Residual settlement measured by leveling was within $\pm 1 \mathrm{~mm}$, indicating that there was no appreciable settlement. Similarly, no appreciable pore water pressure was measured.

\section{Performance evaluation by FEM analysis}

\subsection{Loading test simulation}

Linear elastic static FEM analysis was carried out to investigate the resilient deformation characteristics of the integrated RC roadbed. Figure 10 shows the FEM analysis model used to simulate the loading test. Young's modulus was determined based on the ground investigation in consideration of the stress and strain levels.

Figure 11 shows the results of the loading tests and the FEM analysis. It indicates that FEM analysis can sufficiently simulate the resilient deformation behavior of integrated $\mathrm{RC}$ roadbed in the loading test. Here, the reinforced concrete layer was treated as a homogeneous concrete slab in which the concrete itself took charge of the tension stress.

In Fig. 11, the displacement of the integrated RC roadbed in the loading test was smaller than that in the FEM analysis. Roadbed displacement was mainly dominated by subgrade deformation, indicating that the subgrade demonstrated stiffer behavior in the loading test than in the FEM analysis. This is partly due to the strain rate effect of the clay subgrade. It is considered that the clay subgrade exhibited higher stiffness in the $20 \mathrm{~Hz}$ cyclic loading test than in the triaxial compression test due to the strain rate effect[2]. However, the resonance test results showed that the maximum displacement around the resonance frequency became 3.5 times larger than that around $20 \mathrm{~Hz}$ in the cyclic loading test. It should therefore be noted that the maximum displacement may become larger under conditions of dynamic loading.

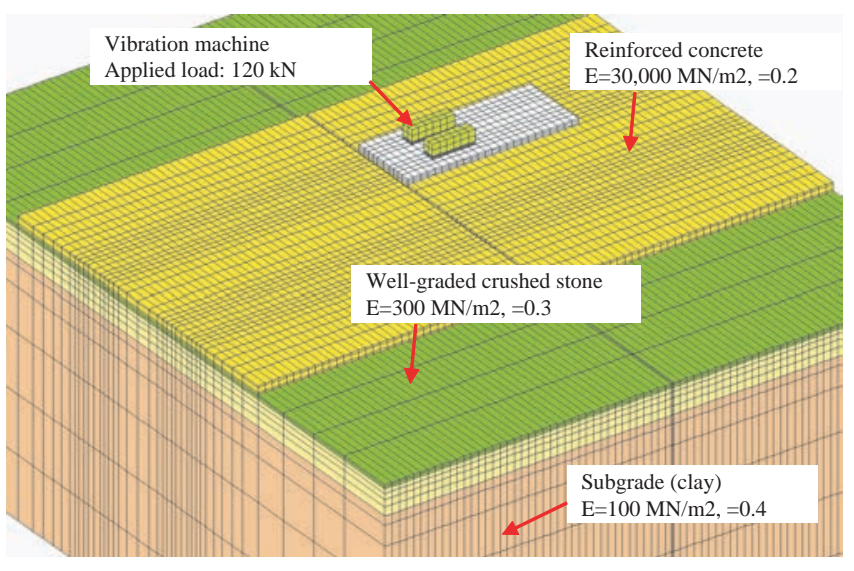

Fig. 10 FEM analysis model

\subsection{Comparison of standard RC roadbed and integrated $\mathrm{RC}$ roadbed}

The deformation characteristics of standard RC road-

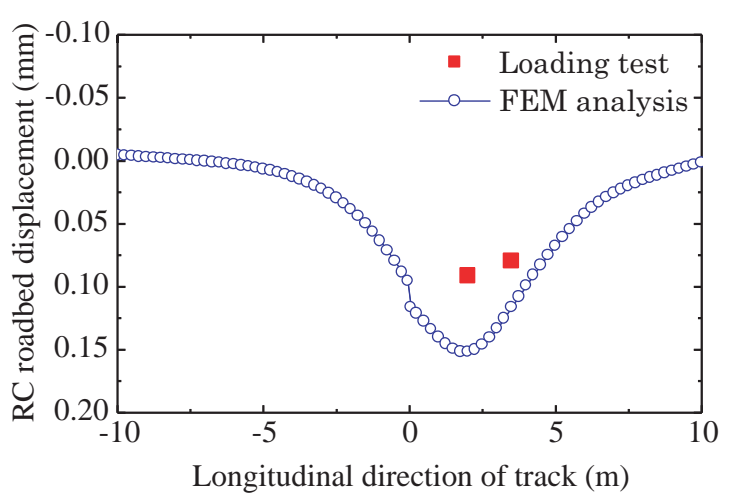

(a) $\mathrm{RC}$ roadbed vertical displacement

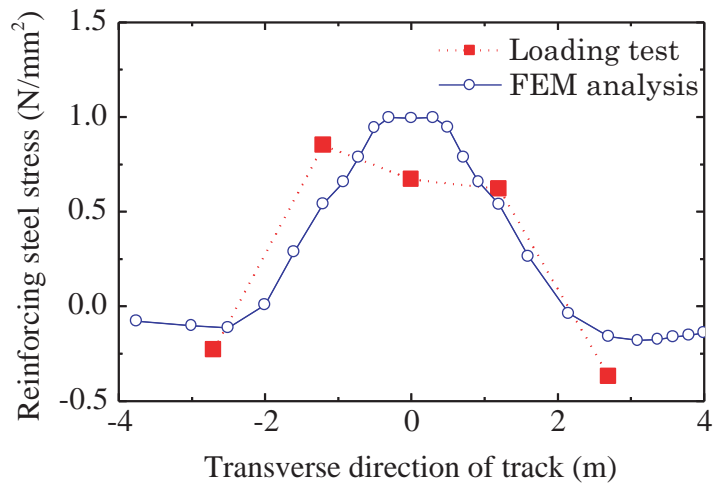

(b) Reinforcing steel horizontal stress

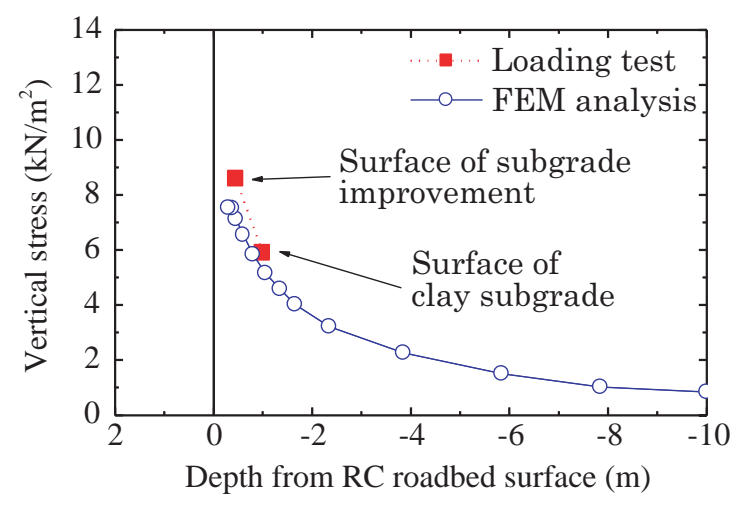

(c) Subgrade vertical stress

Fig. 11 Cyclic loading test and FEM analysis

bed and integrated $\mathrm{RC}$ roadbed were examined based on the results of the FEM analysis. In this examination, the Young's modulus of the subgrade was $40 \mathrm{MN} / \mathrm{m}^{2}$ (corresponding to a strain level of $10^{-4}$ ), and a wheel load of 85 $\mathrm{kN}$ was applied. Figure 12 shows that deformation in the standard RC roadbed is concentrated beneath the loading point. On the other hand, deformation in the integrated RC roadbed was widely distributed in the transverse direction of the track.

Table 3 shows a comparison of $\mathrm{RC}$ roadbed displacement, reinforcing steel stress and subgrade stress between the standard $\mathrm{RC}$ roadbed and the integrated $\mathrm{RC}$ roadbed, and indicates that integrated $\mathrm{RC}$ roadbed effectively reduces deformation and stress in the roadbed itself and the subgrade. 
Table 3 Comparison of standard RC roadbed and integrated RC roadbed

\begin{tabular}{|l|c|c|c|}
\hline & Integrated & Standard & Integrated/Standard \\
\hline Displacement of RC roadbed & $0.60 \mathrm{~mm}$ & $0.71 \mathrm{~mm}$ & 0.85 \\
\hline Reinforcing steel stress & $2.08 \mathrm{~N} / \mathrm{mm}^{2}$ & $2.33 \mathrm{~N} / \mathrm{mm}^{2}$ & 0.89 \\
\hline Vertical stress (subgrade improvement) & $10.5 \mathrm{kN} / \mathrm{m}^{2}$ & $28.6 \mathrm{kN} / \mathrm{m}^{2}$ & 0.37 \\
\hline Vertical stress (clay subgrade) & $6.89 \mathrm{kN} / \mathrm{m}^{2}$ & $9.02 \mathrm{kN} / \mathrm{m}^{2}$ & 0.76 \\
\hline
\end{tabular}

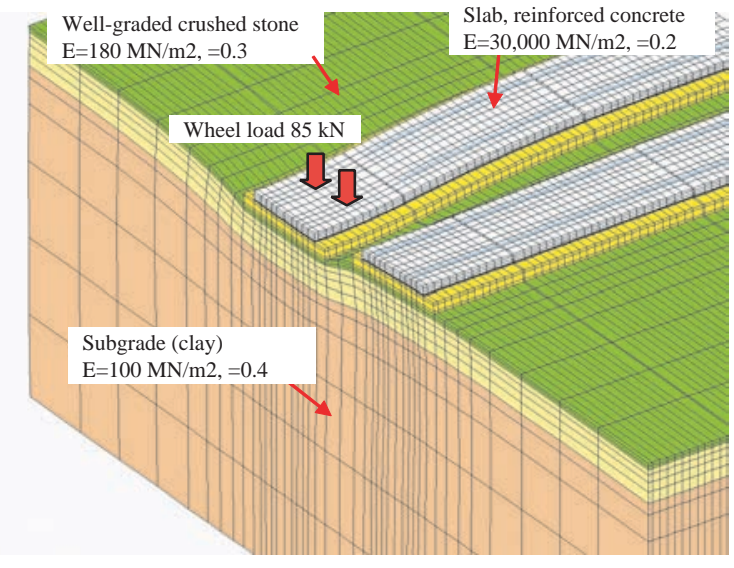

(a) Standard RC roadbed

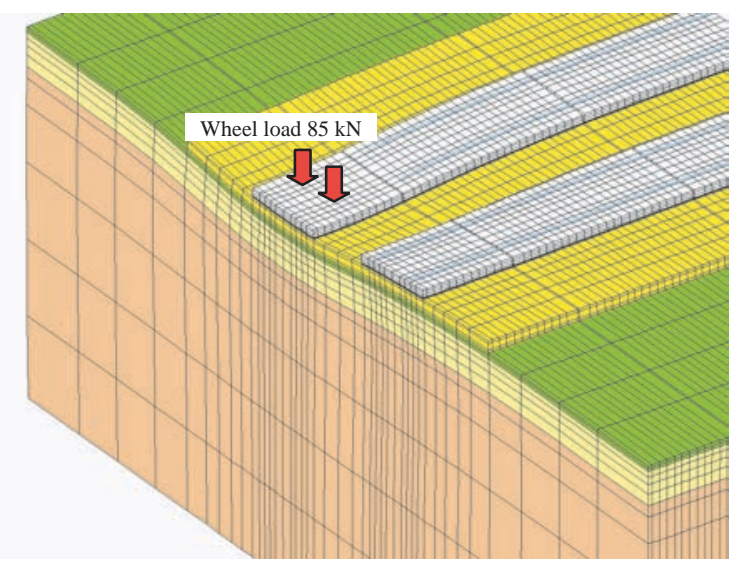

(b) Integrated RC roadbed

Fig. 12 Deformation of standard RC roadbed and integrated $R C$ roadbed

\subsection{Performance evaluation of integrated RC roadbed}

The displacement of the integrated $\mathrm{RC}$ roadbed in the case of a subgrade strain level of $10^{-4}$ was $0.60 \mathrm{~mm}$ under a wheel load of $\mathrm{P}=85 \mathrm{kN}$. When the impact load of $3.0 \times \mathrm{P}$ is taken into consideration following the design standard of slab track, the displacement of the integrated $\mathrm{RC}$ roadbed will be $1.80 \mathrm{~mm}$. However, considering that the dynamic response around the resonance frequency is 3.5 times larger than that outside the resonance frequency, the displacement of the roadbed will become 2.1 $\mathrm{mm}$. In general, displacement of $3-4 \mathrm{~mm}$ is allowed for rail deformation. Accordingly, displacement of the integrated $\mathrm{RC}$ roadbed on clay subgrade is small enough for safe train operation. Considering that the displacement of the integrated roadbed was $0.1 \mathrm{~mm}$ in the cyclic loading test, displacement will be much smaller in practice.

Safety for fatigue breakdown of the integrated RC roadbed was then evaluated. The reinforcing steel stress obtained by FEM analysis was $2.08 \mathrm{~N} / \mathrm{mm}^{2}$. However, this value was obtained from a condition in which there was no cracking of the concrete itself. In general, the tensile stress of concrete itself is not considered in the design of reinforced concrete. The reinforcing steel stress without tension of concrete became $24.2 \mathrm{~N} / \mathrm{mm}^{2}$. Here, a design condition of 60 trains each consisting of 12 coaches passing per day was assumed. According to the design standards for concrete structures, the design fatigue strength is $144.3 \mathrm{~N} / \mathrm{mm}^{2}$, which is much larger than the reinforcing steel stress induced in the integrated $\mathrm{RC}$ roadbed even when impact loads are considered.

Finally, the possibility of residual settlement of integrated RC roadbed was examined. The vertical stress induced in the clay subgrade obtained by FEM analysis was $6.89 \mathrm{kN} / \mathrm{m}^{2}$. The maximum deviator stress obtained in the triaxial compression test was $75 \mathrm{kN} / \mathrm{m}^{2}$, which was ten times larger than the vertical stress induced in the clay subgrade. Furthermore, integrated RC roadbed is constructed on cutting sections where the subgrade is sufficiently over-consolidated diluvial clay. Accordingly, it can be concluded that excessive residual settlement will not be induced by train loads.

\section{Conclusion}

In this study, the performance of integrated RC roadbed on clay subgrade was evaluated. The results showed that the roadbed can reduce stress and strain in the roadbed itself and in the subgrade. The displacement of the integrated RC roadbed was small enough to ensure the running safety of trains. Additionally, the reinforcing steel stress in the roadbed was small enough to prevent fatigue failure, and the stress level induced in the clay subgrade was small enough to avoid residual settlement caused by train loads.

\section{References}

[1] Ando, K., Sunaga, M., Sekine, E., Aoki, H., Yonezawa, T., Okamoto, T., "Practical Use of Slab Track Structure with Reinforced Concrete Bed on Earthworks," RTRI Report, Vol. 13, No. 5, pp. 5 - 10, 1999 (in Japanese).

[2] Momoya, Y., Ishii, T. and Tatsuoka, F., "Strain rate dependency on the deformation characteristics of NC clay and prediction of undrained creep," Presented at $33^{\text {rd }}$ Annual Conference of the Japanese Geotechnical Society, pp. $615-616,1998$ (in Japanese). 